استحثاث كالس السيقان وتمايزنباتات المطاط Ficus elastica Decora منه ومن القمم النامية في الوسط الزبان

\title{
Stimulation of Stem Callus and Regenration of Ficus elastica "Decora" and from Apical Tips in vitro
}

$$
\begin{aligned}
& \text { مزاحم قاسم الملاح } \\
& \text { كلية التربية / جامعة الموصل } \\
& \text { رغد محمد عبد الله }
\end{aligned}
$$

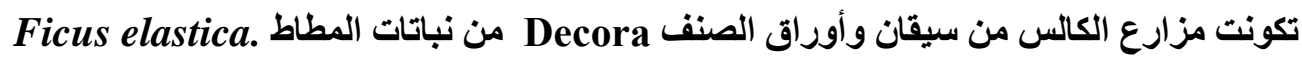

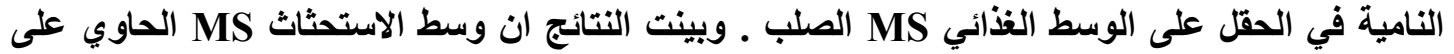

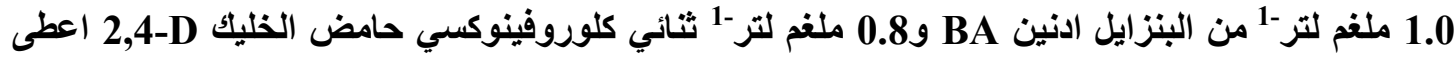

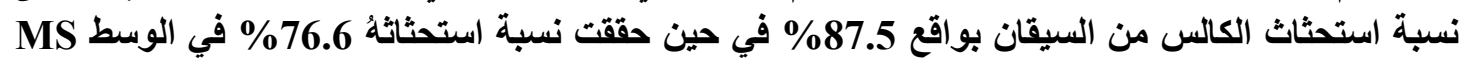

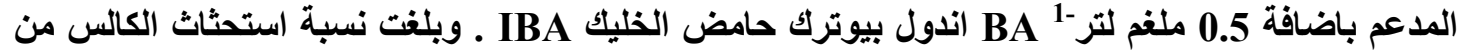

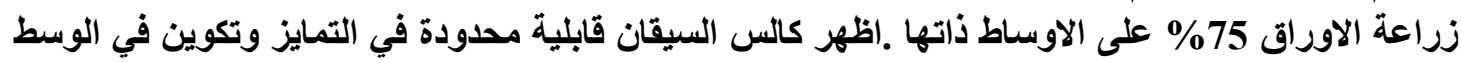

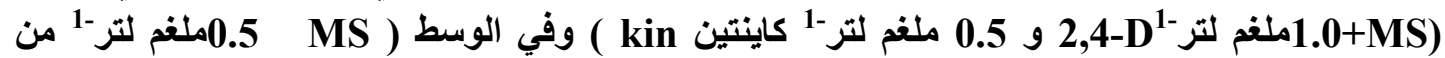

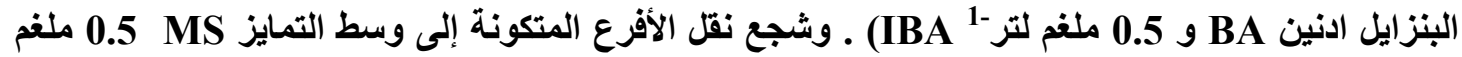

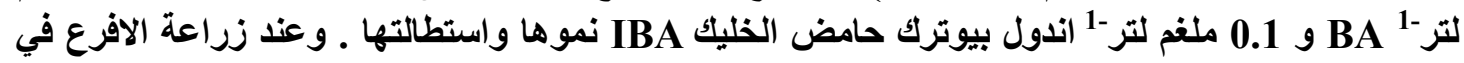

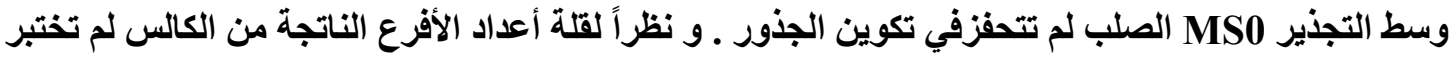

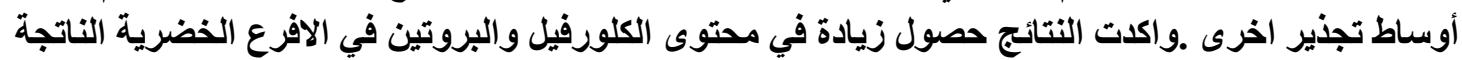

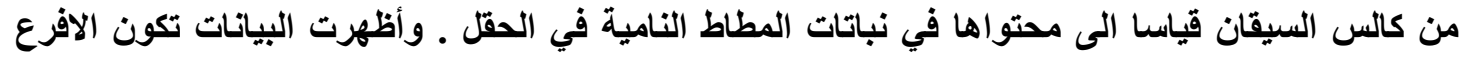

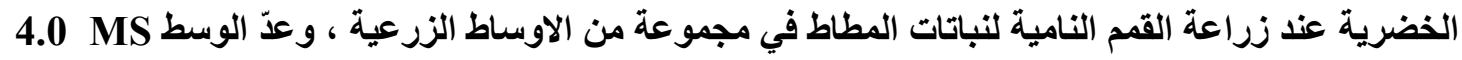

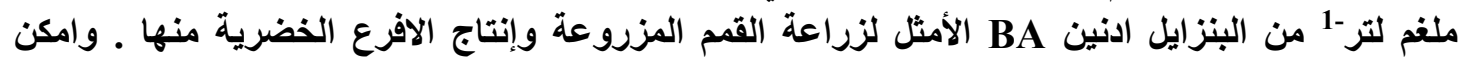

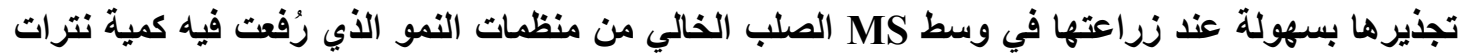

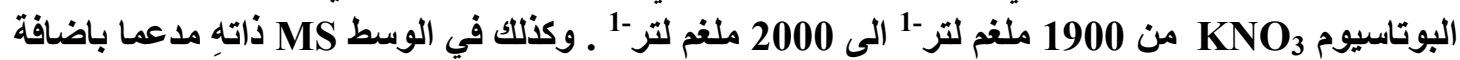

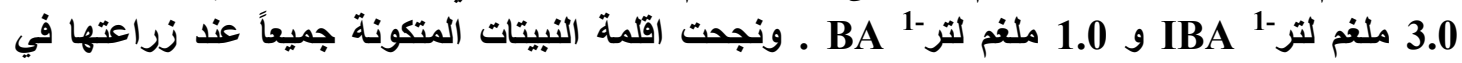

Abstract

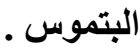

Calli cultures of stems and leaves explants excised from field -grown rubber, Ficus elastica Decora, plants were formed on agar-solidified Murashige and Skoog (MS) medium. The results proved that MS medium supplemented with 1.0 mg $L^{-1}$ benzyl adenin (BA) and $0.8 \mathrm{mg}^{-1}$ 2,4-dichloro-phenoxy acetic acid (2,4D) was suitable to stimulate stem's callus at ratio $87.5 \%$. Whereas supplementation of MS medium with $0.5 \mathrm{mg} \mathrm{L}^{-1}$ of both BA and Indole -3butyric acid (IBA)encouraged callus formation to reach 76.6\%. Leaves showed responses for callus initiation up to $\mathbf{7 5 \%}$ at the same media. Stem calli showed limited ability to regenerate shoots on both agar solidified MS medium containing $1.0 \mathrm{mg} \mathrm{L}^{-1}$ 2,4-D and kinetin (kin) $0.5 \mathrm{mg} \mathrm{L}^{-1}$ and MS medium supplemented with $0.5 \mathrm{mg} \mathrm{L}^{-1}$ of both $B A$ and IBA. Transferring of shoots to differentiation medium (MS+0.5 mg L $\mathrm{L}^{-1} \quad \mathrm{BA}+0.1 \mathrm{mg} \mathrm{L}^{-1} \quad$ IBA) stimulated the growth and elongation of these shoots. Shoots were transferred to agar-solidified 
MS medium free from growth regulators failed to form roots. Because of the less number of shoots, other rooting media were not tested. The data showed, that shoot tips succeeded to regenerate shoots when they were cultured in different MS. The results proved clear increase in chlorophyll and protein content of the rubber shoots as compared with content of field grown rubber plants. It was noticed that agar-solidified MS medium supplemented with $4.0 \mathrm{mg} \mathrm{L}^{-1} \mathrm{BA}$ was considered the optimum medium for shoots regeneration. All plants regenerated from shoot tips were readily rooted in agar-solidified MS medium with increasing Potassium Nitrate $\mathrm{KNO}_{3}$ from $1900 \mathrm{mg} \mathrm{L}^{-1}$ to $2000 \mathrm{mg} \mathrm{L}^{-1}$, and at the same medium supplemented with $3.0 \mathrm{mg} \mathrm{L}^{-1}$ IBA and $1.0 \mathrm{mg} \mathrm{L}^{-1}$ BA. All these plants were successfully acclimated and transferred to peat moss.

المقدمة تنتمي نباتات المطاط. Ficus elastica الصنف Decora ، الى العائلة التوتية Moraceae . ويطلق على هذه

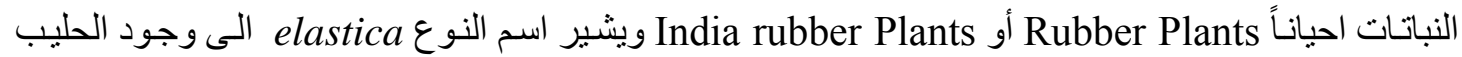

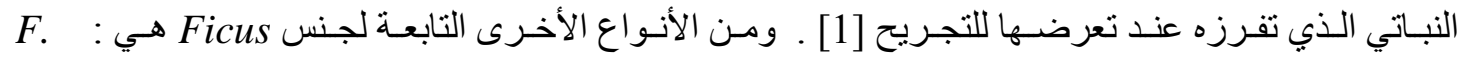
[2] F. religiosa, F. ribes , F. carica , F. deltoid , F. benjamina ,benghalensis

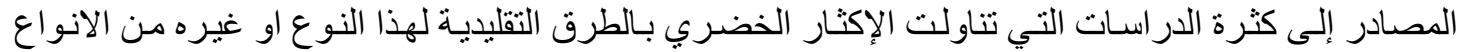

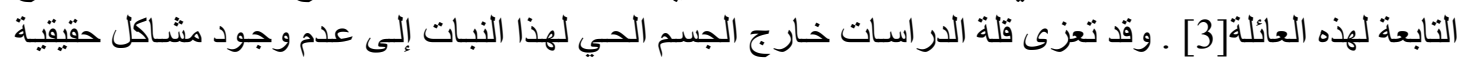

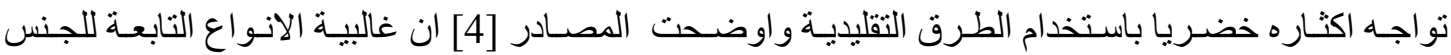
باستثناء النوع Ficus

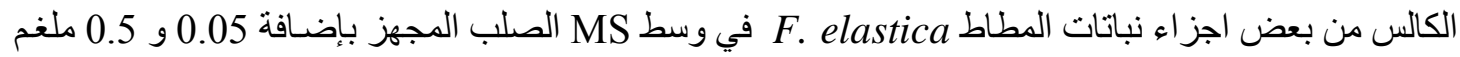
لتر -

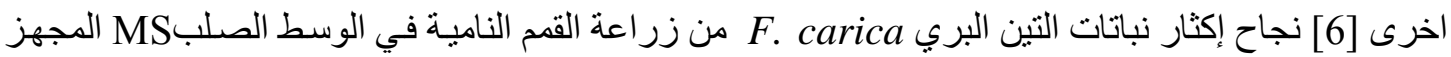

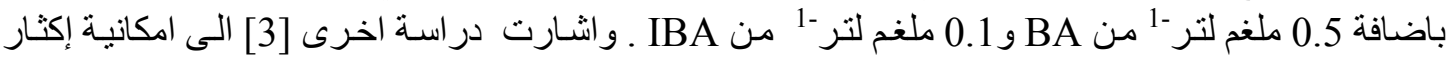

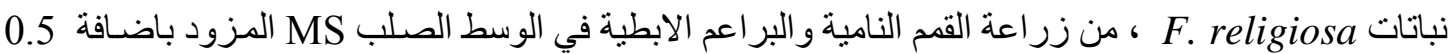

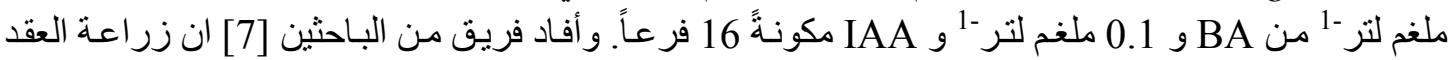

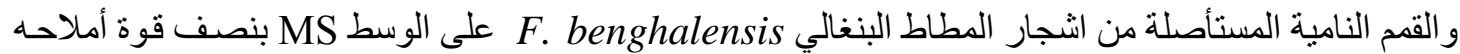

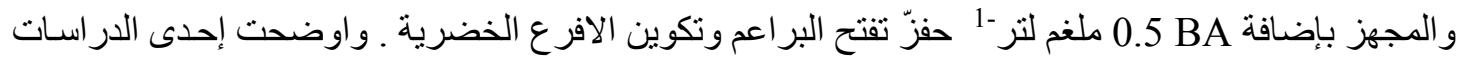

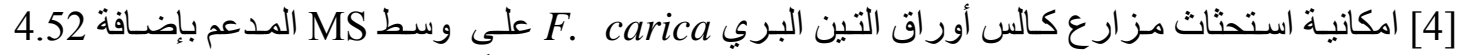

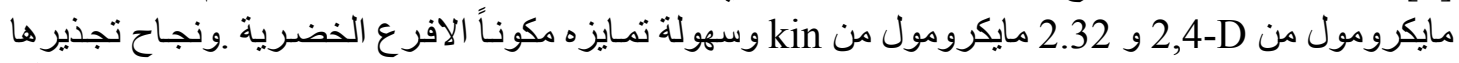

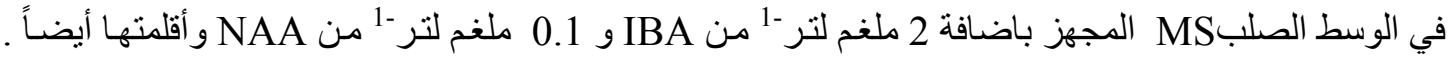

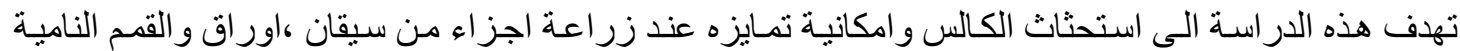

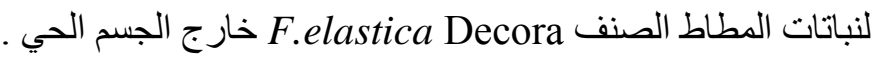
المواد وطرائق العمل

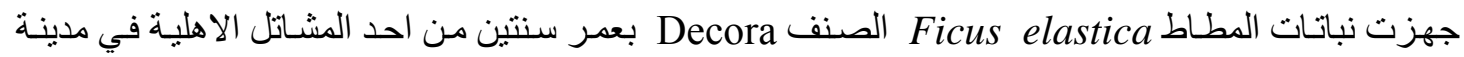

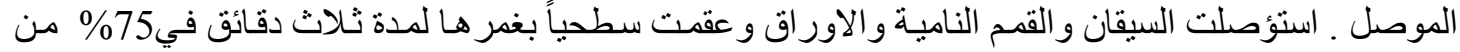

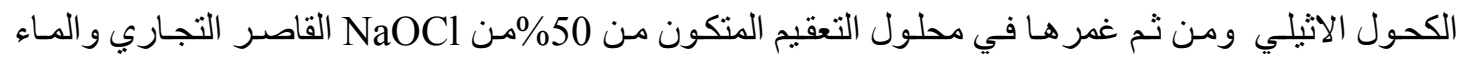

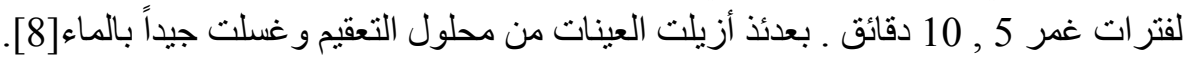

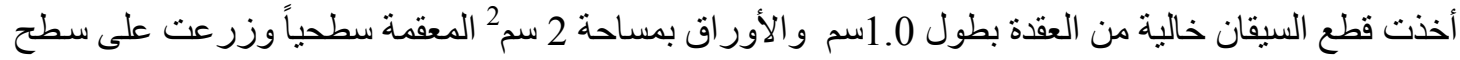

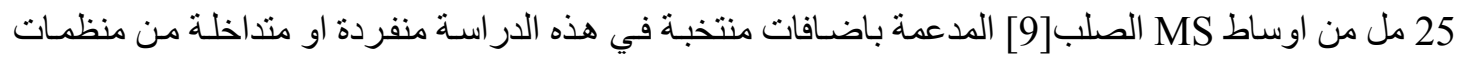

MSO (مقارنة)

$\mathrm{MS}+\mathrm{BA} 2.0 \mathrm{mgL}^{-1}$ 


$$
\begin{aligned}
& \mathrm{MS}+\mathrm{BA} 3.0 \mathrm{mgL}^{-1} \\
& \mathrm{MS} \text { + BA } 4.0 \mathrm{mgL}^{-1} \\
& \mathrm{MS} \text { + BA } 0.9 \mathrm{mgL}^{-1}+\mathrm{NAA} 0.5 \mathrm{mgL}^{-1} \\
& \mathrm{MS} \text { + BA } 1.0 \mathrm{mgL}^{-1}+\mathrm{NAA} 1.0 \mathrm{mgL}^{-1} \\
& \mathrm{MS}+\mathrm{BA} 2.0 \mathrm{mgL}^{-1}+\mathrm{NAA} 0.5 \mathrm{mgL}^{-1} \\
& \mathrm{MS}+\mathrm{BA} 1.0 \mathrm{mgL}^{-1}+2,4-\mathrm{D} 0.8 \mathrm{mgL}^{-1} \\
& \mathrm{MS}+\mathrm{BA} 0.5 \mathrm{mgL}^{-1}+\mathrm{IBA}_{0.5 \mathrm{~mL}^{-1}} \\
& \mathrm{MS}+\mathrm{BA} 0.5 \mathrm{mgL}^{-1}+\mathrm{IBA}_{0.1 \mathrm{mgL}^{-1}}
\end{aligned}
$$$$
\mathrm{MS}+2,4-\mathrm{D} 1.0 \mathrm{mgL}^{-1}+\mathrm{Kin}_{0.5 \mathrm{mgL}^{-1}[4]}
$$$$
\mathrm{MS}+2,4-\mathrm{D} 0.5 \mathrm{mgL}^{-1}+\mathrm{Kin}_{0.5} \mathrm{mgL}^{-} \text {[4] }
$$$$
\text { جززت قطع بوزن غر ام واحد من كلا نوعي الكالس المستحث من السيقان و الاور اق على الاوساط المبينة ادناه . }
$$$$
\text { MSO ( المقارنة ) }
$$$$
\mathrm{MS}+\mathrm{BA} 1.5 \mathrm{mgL}^{-1}+2,4-\mathrm{D} 0.5 \mathrm{mgL}^{-1}
$$$$
\mathrm{MS}+\mathrm{BA} 2.0 \mathrm{mgL}^{-1}+2,4-\mathrm{D} 0.75 \mathrm{mgL}^{-1}
$$$$
\mathrm{MS}+\text { Kin } 0.5 \mathrm{mgL}^{-1}+2,4-\mathrm{D} 1.0 \mathrm{mgL}^{-1}
$$$$
\mathrm{MS}+\mathrm{Kin} 1.0 \mathrm{mgL}^{-1}+2,4-\mathrm{D} 0.75 \mathrm{mgL}^{-1}
$$$$
\mathrm{MS}+\mathrm{Kin} 2.0 \mathrm{mgL}^{-1}+2,4-\mathrm{D} 0.5 \mathrm{mgL}^{-1}
$$$$
\mathrm{MS}+\mathrm{BA} 0.5 \mathrm{mgL}^{-1}+\mathrm{IBA} 0.1 \mathrm{mgL}^{-1} \text { [6] }
$$$$
\text { استخدمت قنانٍ زجاجية حجم } 100 \text { مل تحوي على } 25 \text { مل من وسط التمايز وبمعدل قطعـة / قنينـة ، استؤصلت }
$$

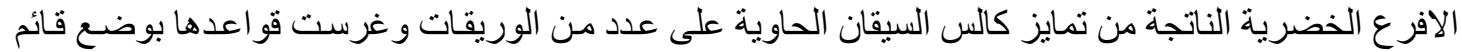

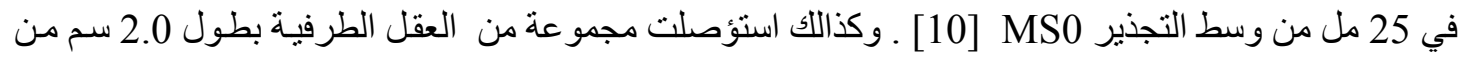

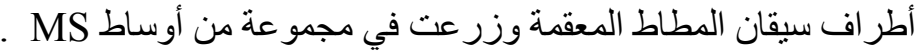

MSO (مقارنة)

$\mathrm{MS}+\mathrm{BA} 4.0 \mathrm{mgL}^{-1}$.

$\mathrm{MS}+\mathrm{BA} 5.0 \mathrm{mgL}^{-1}$.

$\mathrm{MS}+\mathrm{Kin} 2.0 \mathrm{mgL}^{-1}+2,4-\mathrm{D} 1.0 \mathrm{mgL}^{-1}$.

$\mathrm{MS}+\mathrm{BA} 0.5 \mathrm{mgL}^{-1}+\mathrm{IBA}_{0.1 \mathrm{mgL}^{-1}[6]}$

ازيلت الافرع النامية الناتجة من تحفيز نمو البر اعم الابطية وزرعت في أوساط MS الصلب بكامل او نصف

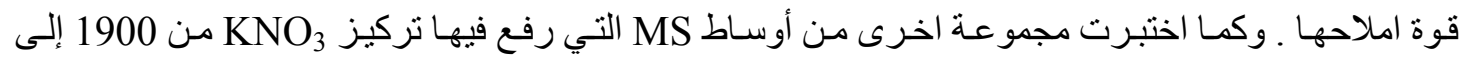

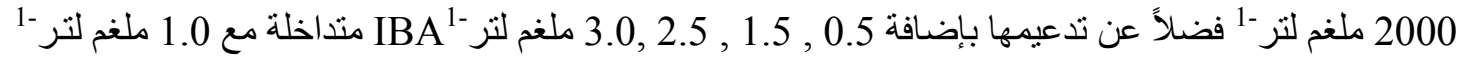

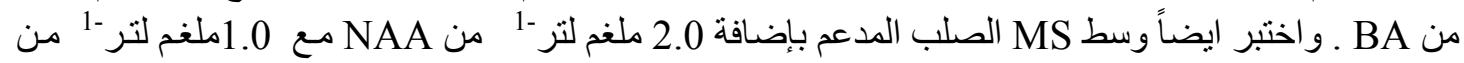
ـ وبعد تكوينها الجذور ازيلت النبيتات من الوسط و غسلت جذور ها بالماء لاز الة بقايا الوسط ومن ثم غرست

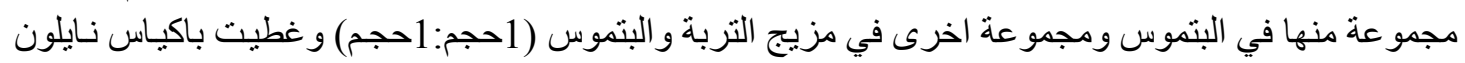

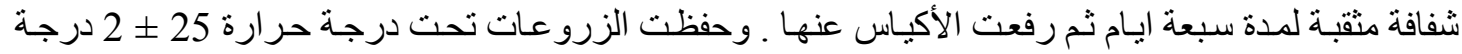

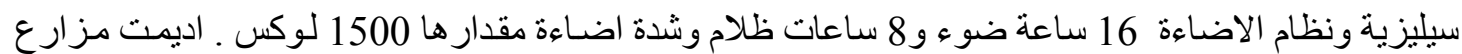

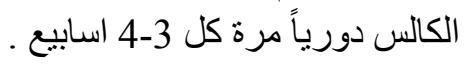

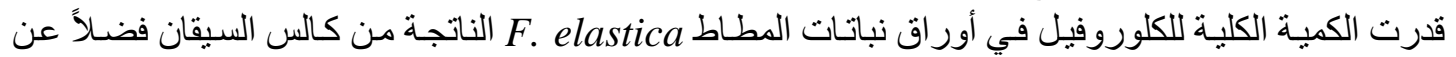

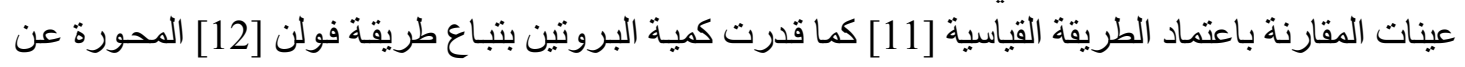
طريقة لوري [13] ـ وتم حساب الانحر اف القياسي للمنوسطات .

النتائج استحثاث الكالس من السيقان والأوراق وإدامتها برهنت النتائج تكوين مزارع كالس السيقان على مجموعة متباينة من أوساط الاستحثاث ـ ـوسجلت أعلى نسبة

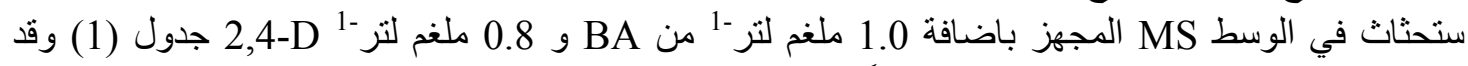

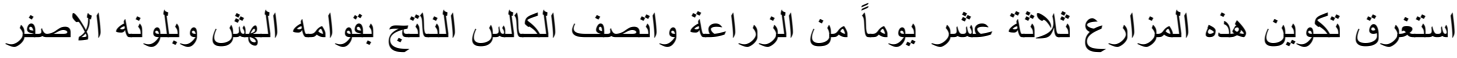


المائل إلى الابيض شكل (A.1) . واتضح عموماً وجود صعوبات في استحثاث كالس الاوراق بدلالة ضعف

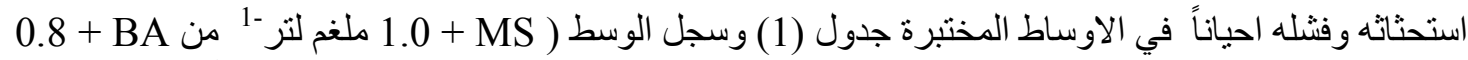

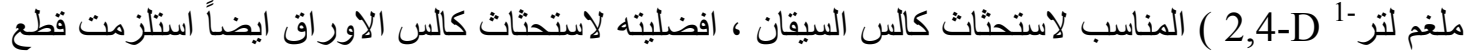

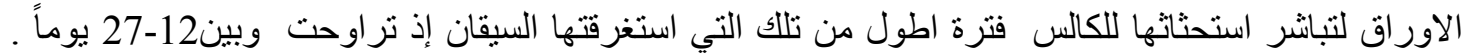

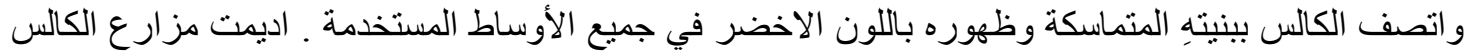

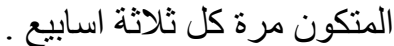
جدول (1): استحثُث الكالس سيقان واوراق نباتات المطاط Ficus elastica Var. Decora المزروعة في الوسط MS الصلب

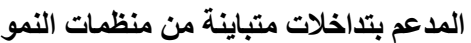

\begin{tabular}{|c|c|c|c|c|c|c|}
\hline \multirow{2}{*}{$\begin{array}{l}\text { الكتالسثاث } \\
\text { (\%) }\end{array}$} & \multicolumn{2}{|c|}{ عدد قطع الأوراق } & \multirow{2}{*}{ الاستحثاث } & \multicolumn{2}{|c|}{ عدد قطع السيقان } & \multirow[t]{2}{*}{ أوساط الاستحثثث } \\
\hline & المستحثة & المختبرة & & المستحثة & المختبرة & \\
\hline $\mathbf{0}$ & $\mathbf{0}$ & 10 & 0.0 & $\mathbf{0}$ & 20 & MS0 (مقارنة) \\
\hline 40.0 & 4 & 10 & 43.4 & 10 & 23 & MS + BA 2.0 \\
\hline 37.5 & 3 & 8 & 13.3 & 2 & 15 & MS + BA 3.0 \\
\hline 33.3 & 3 & 9 & 28.5 & 4 & 14 & MS + BA 4.0 \\
\hline 50 & 5 & 10 & 60.0 & 12 & 20 & $\begin{array}{c}\text { MS + BA } 0.9+ \\
\text { NAA } 0.5\end{array}$ \\
\hline 22.2 & 2 & 9 & 53.0 & 8 & 15 & $\begin{array}{c}\text { MS + BA } 2.0+ \\
\text { NAA } 0.5\end{array}$ \\
\hline 75.0 & 15 & 2 & 87.5 & 35 & 40 & $\begin{array}{c}\text { MS +BA } 1.0+ \\
2,4-D ~ 0.8\end{array}$ \\
\hline 44.4 & 4 & 9 & 63.3 & 19 & 30 & $\begin{array}{c}\text { MS + 2,4-D } 1.0 \\
+ \text { Kin } 0.5\end{array}$ \\
\hline 28.5 & 2 & 7 & 68.1 & 15 & 22 & $\begin{array}{c}\text { MS + 2,4-D 0.5 } \\
\quad+\text { Kin 0.5 }\end{array}$ \\
\hline $\mathbf{0}$ & $\mathbf{0}$ & 10 & 33.3 & 5 & 15 & $\begin{array}{c}\text { MS + BA } 0.5+ \\
\text { IBA } 0.1\end{array}$ \\
\hline $\mathbf{0}$ & $\mathbf{0}$ & 8 & 76.6 & 23 & 30 & $\begin{array}{c}\text { MS + BA } 0.5+ \\
\text { IBA } 0.5\end{array}$ \\
\hline $\mathbf{0}$ & $\mathbf{0}$ & 7 & $\mathbf{0}$ & $\mathbf{0}$ & 7 & $\begin{array}{c}\text { MS }+ \text { BA1.0 + } \\
\text { IBA1.0 }\end{array}$ \\
\hline
\end{tabular}



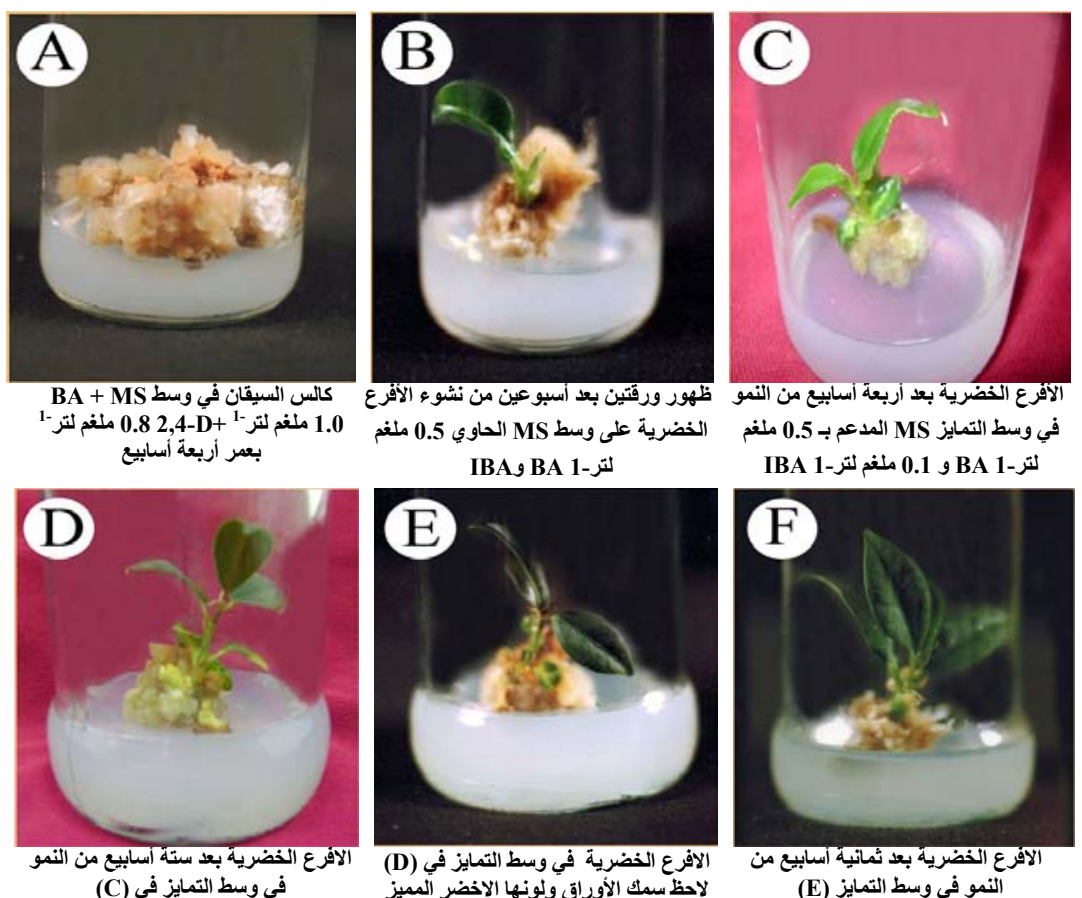

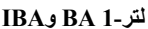

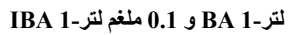

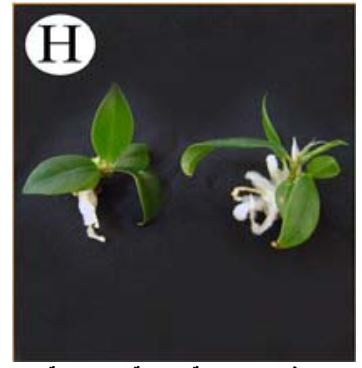

الافرع الخضرية الناتجة من زراعة القمم النامية

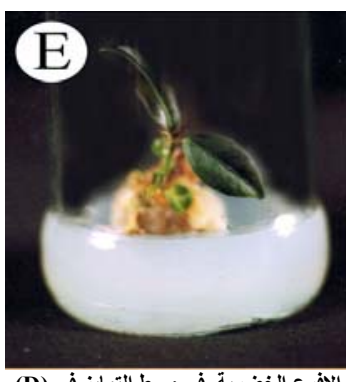

الافرع الخضرية في وسط التمايز في (D) لاحظ سمك الأوراق ولونها الاخضر المثيز

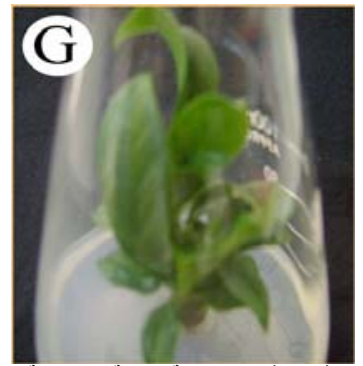

جذور الافرع الخضرية الناتجة من زراعة المّم النامية بعد ثلاثة اسابيع من نقلئه

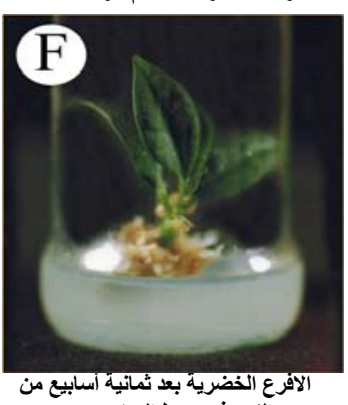

(E) النمو في وسط التمائرئية

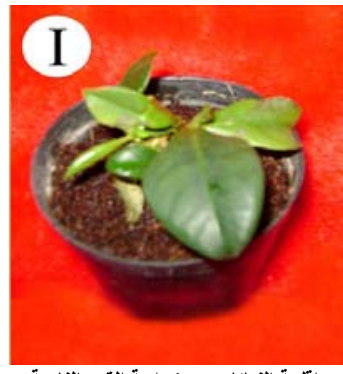

اقلمة النباتات من زراعة القمم النامية في البتموس

شكل (1): مراحل تمايز الكالس (A-f) السيقان وتكوين الافرع الخضرية من زراعة القم النامية (G-I) لنبات المطاط Ficus elastica

\section{تكوين الأفرع الخضرية من كالس السيقان} أظهر كالس السبقان أثناء ادامته قدرته المحدودة على التمايز جدول (2) ـ حين نقلته الثالثة. فقد لوحظ نشو التهاء

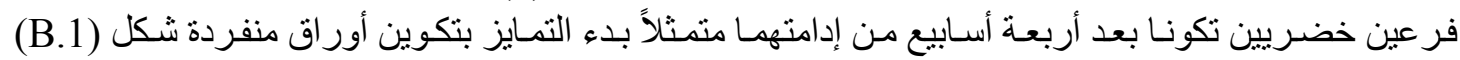
وتطور ظهور ها في الوسط MS الحاوي على IBA , BA شكل (D.C.1) بينما فشلت بقية قطع كالس السيقان

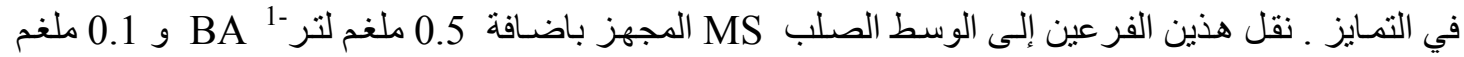

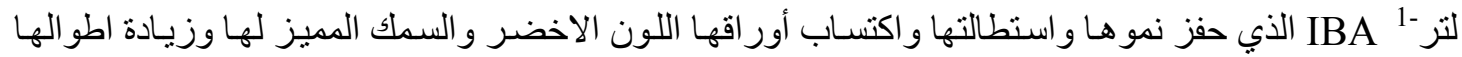

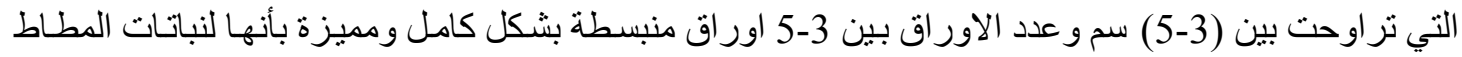

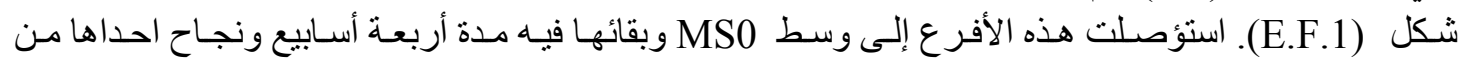
الاستمر ار بالنمو و الزيادة في الحجم دون تجذيره وموت الفرع الثاني.علما بان بقيةاوساط التمايز المختبرة فثلت

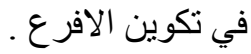
جدول (2): تمايز كالس سيقان المطاط Ficus lastica Var. Decora المزروعة في اوساط MS الصلبة المدعمة بتداخلات من منظمات النمو

\begin{tabular}{|c|c|c|c|}
\hline عدد الفرع المتكونة & علد القطّ & علد قطع الكالس & اوساط التمايز \\
\hline 1 & 1 & 20 & $\mathrm{MS}+2,4-\mathrm{D} 1.0+\operatorname{Kin} 0.5$ \\
\hline 1 & 1 & 25 & MS + BA $0.5+$ IBA 0.5 \\
\hline
\end{tabular}


تكوين نباتات المطاط من زراعة القمم النامية

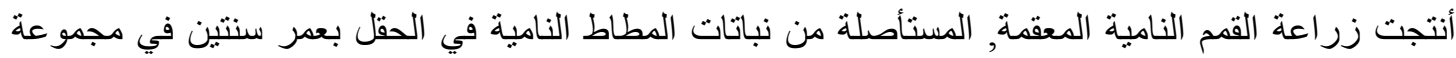

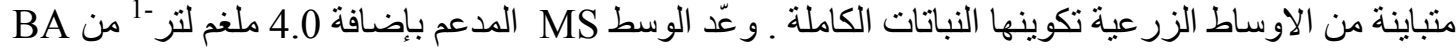

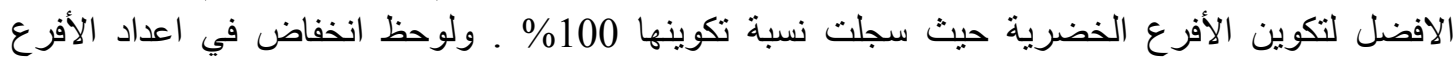

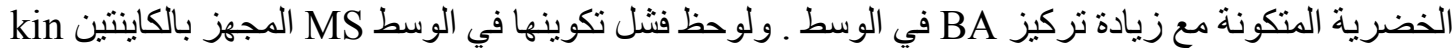

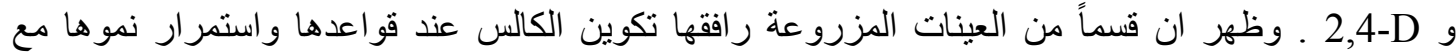
تكوينها للافرع الخضرية شكل (G.1) . و وعموماً بدأت الأفرع الخضرية بالظهور في الأسبوع الخامس من

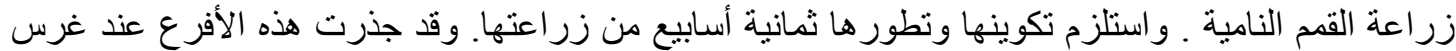

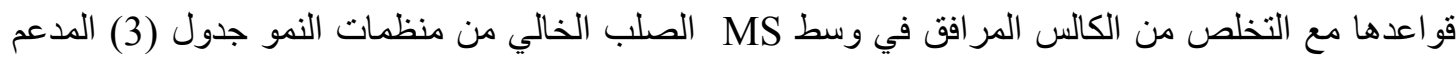
بإضافة 2000 ملغم لتر-1 بدلاً 1900 ملغم لتر -1 من نترات البوتأسيوم

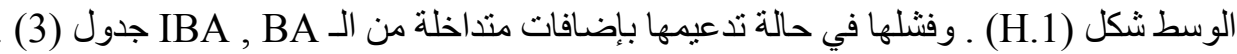

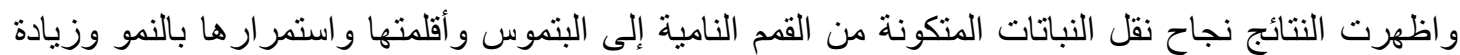
ارتفاعاتها لتصل إلى (5-7)سم شكل (I.1) ـ بينما لوحظ على النباتات المنقولة إلى مزيج التربة والبتموس

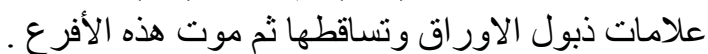
F. elastica Var. جاول (3): تاثير الاوساط الزرعية في تجذير الافرع الخضرية الناتجة من زراعة القمم النامية لنباتات المطاط Decora

\begin{tabular}{|c|c|c|c|}
\hline عدد الافرع المنقولة الى & عدد الافرع المجذرة & عدد الافرع المزروعة & اوساط التجذير \\
\hline 7 & 0 & 4 & MS0 \\
\hline $\mathbf{0}$ & 9 & 10 & MSO $^{*}$ \\
\hline $\mathbf{0}$ & $\mathbf{0}$ & 4 & 1/2 MS0 \\
\hline 6 & 6 & 8 & $\mathrm{MS}^{*}+3 \mathrm{IBA}+\mathrm{BA}$ \\
\hline
\end{tabular}

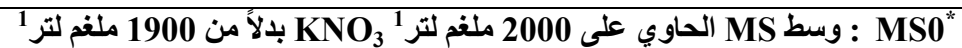

محتوي الكلورفيل والبروتين في اوراق نباتات المطاط الناتجة من كالس السيقان

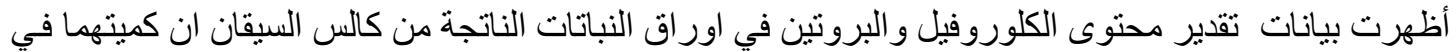

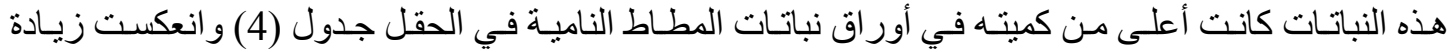

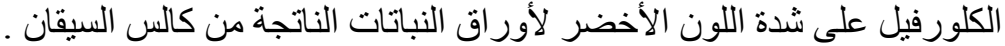
جدول (4): محتوى الكلوروفيل والبروتين في اوراق نباتات المطاط . F. elastica الناتجة من كالس السيقان العينات النباتية

5.8

3.9
2.8

2.0
أوراق النباتات الناتجة من كالس السيقان

أوراق النباتات النامية في الحقل(مقارنة)

المناقشة

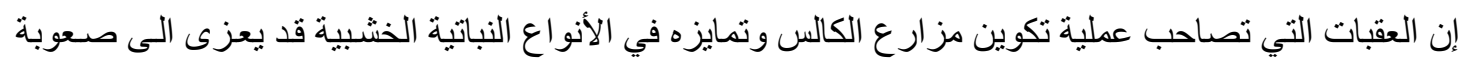

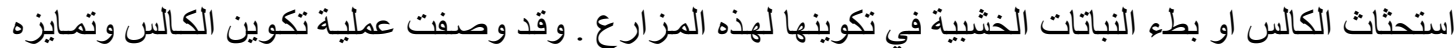

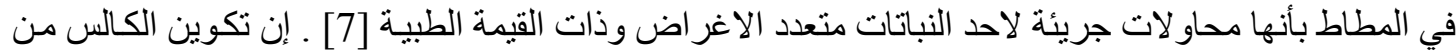

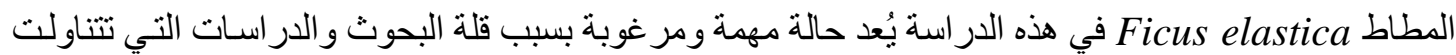

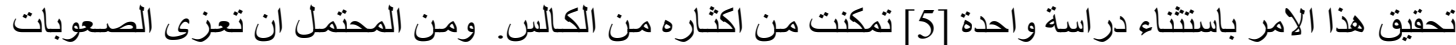

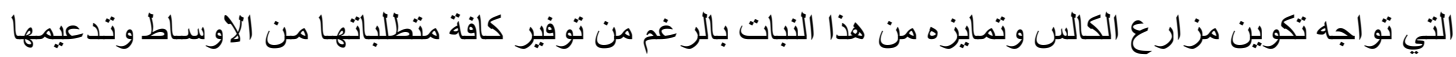

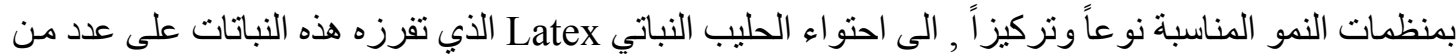

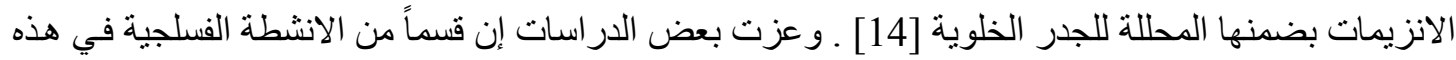

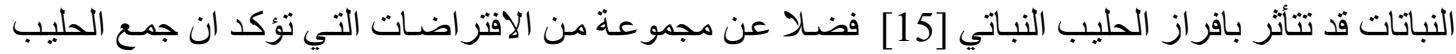


النباتي من نباتات المطاط تتسبب في ضرر انسجته [16] ـ ان توظيف كالس السيقان وزر اعة القمم النامية في

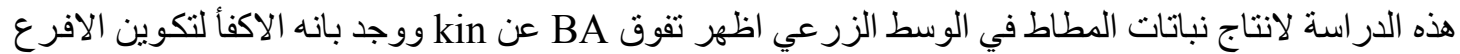

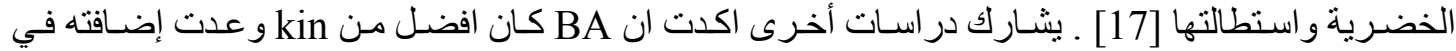

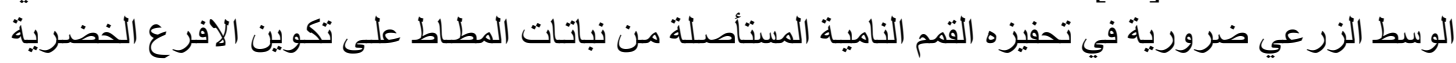

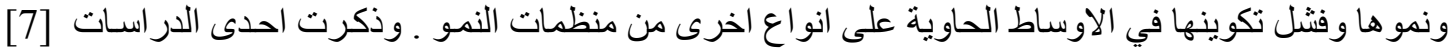

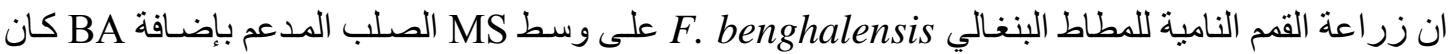

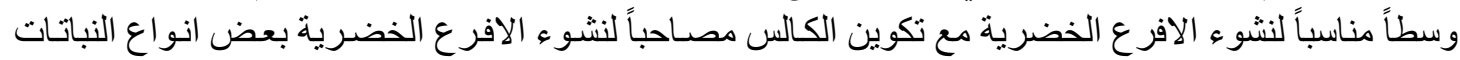

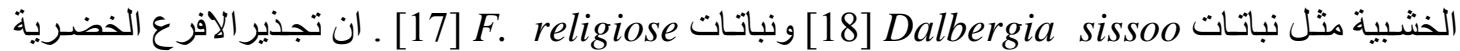

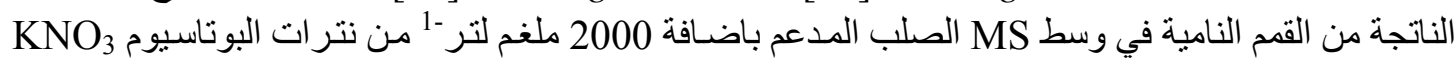
و ايضـا في وسط MS المدعم بإضـافة BA و IBA وفسر كفاءة هذه الاوسـاط من التغلب على مشكلة تجذير

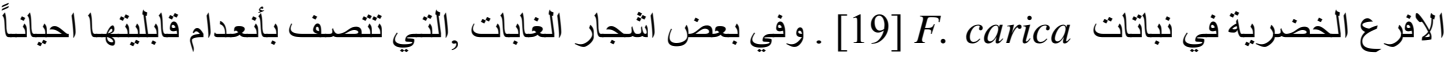
او صعوبة اكثار ها [20] ويحتم اللجوء اللى زر اعة القمم النامية في الاوساط الزرعية للحصول على التى النباتات في

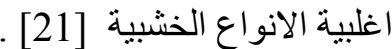

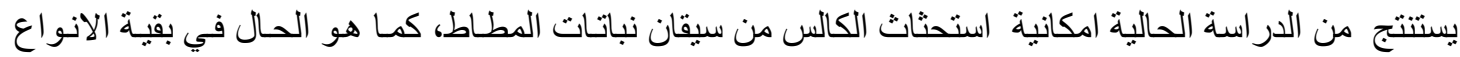

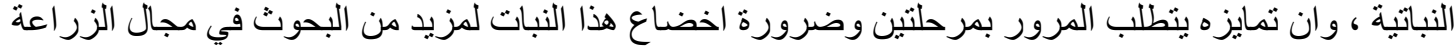

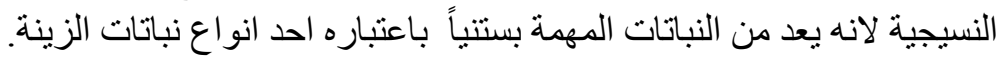

المصادر

1. Starr, F., Starr, K., and Loope, L. (2003). Ficus elastica India rubber tree, Moraceae. United state Geological Survey. Biological Resources Division Haleaka-laField station, Maui , Hawaii ,U.S.A.

2. داؤد ، محمود داؤد ـ (1979) ـ تصنيف اثجار الغابات ـ وزارة التعليم العـالي و البحث العلمي ، جامعة

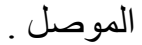

3. Hassan, S., Aforz, F., Jahan, M. and Khatun, R. (2009). In vitro regeneration through apical and axillary shoot proliferation of Ficus religiosa L. A multipurpose woody medicinal plant. Plant Tiss. Cult. Biotech. 19: 71-78.

4. Ferreira, E. A., Pasqual, M. and Rezande, J. C. (2008). 2,4-D and Kinetin in callogenesis of Ficus carica L. Hortic. Sci. 738: 1-2.

5. Kolchugina, I.B. and Markarova, E. N. (2009). Photoheterotrophic Callus Culture Ficus elastica. The formation of polyisoprene synthesis. Mos.Univ. Biol. Sci. Bull. 64: 28-31.

6. Pontikis, C. A. and Melas, P. (1989). Micropropagation of Ficus carica L. Hort. Sci. 21(1) :153-154.

7. Rahman, M., Amin, N. and Hussain, F. (2004). In vitro Propagation of Banyan Tree Ficus benghalensis L. a multipurpose and keystone species of Bangladesh. Plant Tiss. Cult. 14:135-142.

8. Shajahan, A., Kathiravan, K. and Ganapathi, A. (1995). Induction of embryo-like structures by liquid mulberry (Morus alba L.). Breeding Sci. 45:413 - 417.

9. Murashige, T. and Skoog, F. (1962). A revised medium for rapid growth and bioassays with tobacco tissue culture. Physiol. Planta. 15: 473-497.

10. Gomez-Leyva, J. F., Acosta , M. L. A. , Muraria , L. I. G., Espino, S. H., Coravantes, R. F. and Gonzales, A. I. (2008). Multiple shoot regeneration of roselle (Hibiscus sabdariffa L.) from a shoot apex culture system. Int. J. Botany. 4 : 326-330

11. Arnon, D. I. (1949). Copper enzymes in isolated chloroplasts polyphenol 
oxidase in Beta vulgaris. Plant Physiol. 24: 1-15.

12. Schacterale, G. R. and Pollak, R. L. (1973). A simplified methodsfor the quantitative assay of small amount of protein in biologic material. Ann. Bio. Chem. 51: 651-655.

13. Lowery, O. H., Rosebrongh, N. J., Farr, A. L. and Randad, R. J. (1951). Protein measurement with folin-phenol reagent. J. Biol. Chem. 193: 257-265.

14. Kramer, D. E. and Whitaker, J. R. (1964). Properties of the proteolytic enzymes from the Latex of Ficus carica variety kadota. Biol. Chem. 239: 2178-2183.

15. http:// en. Wikipedia. Org/wiki/ Latex

16. Rapepun, W., Piyaporn, P., Kamonwan, K. and Dhirayos W. (2008). A role for a Hevea Latex Lectin-like protein mediating rubber particle aggregation and Latex coagulation. Phytochem. 69: 339-347.

17. Amin, M. N., Habib, M. A., Azad, M. and Akhteruzzaman, M. (2001). Large scale plant regeneration in Ficus religiosa L. $4^{\text {th }}$ Int. Conf. Plant Tiss. Cult. (1-3Nov. Dhaka).

18. Gill, S. S., Gill, R. I. S. and Gosal, S. S. (1997). Rapid propagation of Dalbergia sissoo from mature tree through tissue culture. Plant Tiss. Cult. 7:13-19.

19. Hepaksoy, S. and Aksoy, U. (2006). Propagation of Ficus carica L. Clones by in vitro culture. Biol. Planta. 50: 433-436.

20. Zimmerman, R. H. (1986). Regeneration in woody ornamental and fruit trees. Cell Cult.\&Somat. Cell Gene.Plants 3:243-258.

21. Limburger, R. D. (1980). Tissue Culture of Woody Plants. Buckeye Nurseryman, Columbus, Ohio, U.S.A. 